\title{
Incidence of periodic leg movements and of the restless legs syndrome during sleep following acute physical activity in spinal cord injury subjects
}

\author{
MT de Mello ${ }^{1}$, FAA Lauro ${ }^{2}$, AC Silva $^{2}$ and S Tufik ${ }^{1}$ \\ ${ }^{1}$ Department of Psychobiology - UNIFESP, Escola Paulista de Medicina; ${ }^{2}$ Department of Physiology - UNIFESP, \\ Escola Paulista de Medicina; *Universidadde Federal de Goiás/Catalão, Sao Paulo, Brazil
}

\begin{abstract}
The purpose of the present study was to evaluate sleep patterns and complaints, and Periodic Limb Movement (PLM) and the Restless Legs Syndrome (RLS) in subjects with complete spinal cord injury. Volunteers were submitted to two polysomnograms (Oxford Medilog SAC system - EEG, EMG, EOC): (1) basal night, when the volunteer arrived at the Sleep Center, and (2) after a maximal physical test (Cybex Met 300/increase of 12,5 watts/2 min until exhaustion). Eleven volunteers with complete spinal cord injury between T7-T12 were evaluated. Data were analyzed by the paired Student's $t$ test (total sleeping time) and by the Wilcoxon matched paired test (change of sleep stages, number of awakenings during sleep, latency to REM sleep and leg movements-PLM + RLS). Comparison of sleep recordings from the night before with that from the night after $(12 \mathrm{~h})$ practice of physical activity, showed a significant reduction in all of the sleep parameters. The results indicate that physical activity improves the sleep patterns of spinal cord injured volunteers. In particular, we noticed that PLM and RLS after physical activity were inhibited during sleep.
\end{abstract}

Keywords: spinal cord injury; physical activity; sleep; restless legs syndrome; periodic limb movements

\section{Introduction}

Sleep patterns have been studied in several types of populations. Recently, three studies were published in which sleep pattern, complaints, and the incidence of Periodic Leg Movements (PLM), the Restless Legs Syndrome (RLS) and of myoclonus were evaluated in subjects with spinal cord injury. ${ }^{1-3}$

The Restless Legs Syndrome (RLS) is characterized by disagreeable leg sensations usually prior to sleep onset, that causes an almost irresistible urge to move the legs. ${ }^{4}$ Periodic Leg Movements (PLM) were first described by Lugaresi et $a l^{5}$ and are characterized by periodic episodes of repetitive and highly stereotyped limb movements that occur during sleep. Some factors which might influence the appearance, decrease of symptoms and the frequency of PLM or RLS, are fatigue, intake of cafeinated beverages and exposure to cold. ${ }^{6}$

Comparison of the effects of physical activity on the incidence of PLM, RLS and of myoclonus during sleep in subjects with spinal cord injury, who were or not athletes has been evaluated. ${ }^{2}$ A questionnaire ${ }^{7}$ was

Correspondence: MT de Mello, Department of Psychobiology, Universidade Ferederal de São Paulo-Escola Paulista de Medicina, Rua Botucatu, 862-1 andar São Paulo - SP 04023-062, Brazil applied for spinal cord injured volunteers in Minas Gerais (Brazil), revealing that athletes present reduction of PLM, RLS and of myoclonus. ${ }^{2}$

Decreased $H$ reflex induced by light and high intensity physical activity, and reduction of muscle tension due to aerobic activity were reported. ${ }^{8-10}$ This effect may result from the action of endorphins and catecholamines at the brain and spinal cord levels. ${ }^{9,10}$ The therapeutic effects of opiates on PLM and RLS, suggest that release of endorphins, following physical activity, could be involved in the mechanism of decreased PLM, RLS and myoclonus. ${ }^{4}$

The aim of the present study was to evaluate (by polysomnography) the incidence of PLM and RLS during sleep in a sample of subjects with complete spinal cord section (T7 to T12). Polysomnograms were recorded $16 \mathrm{~h}$ before and $12 \mathrm{~h}$ after an increasing load until maximum effort was reached.

\section{Methods}

Volunteers were contacted through handicapped associations, and selected after a clinical evaluation. Selected volunteers should present stable clinical features, with complete spinal cord injury between T7 and T12, with a lesion of the superior motoneuron, and to participate in regular programs of instructed 
physical activity (at least twice/week). The volunteers were maintained in the Sleep Laboratory of the Clinical Psychobiology Center at Universidade Federal de São Paulo.

Eleven volunteers slept for, at least, 3 consecutive nights in the Laboratory. Polysomnographic recordings were carried out on the 2 nd and 3 rd nights. The 1st night was included for acclimatisation purposes. Recordings were carried out according to the standards for sleeping staging of Rechtschaffen \& Kales, ${ }^{11}$ and electroencephalographic (EEG) recording was obtained according to the international system 10-20. ${ }^{12}$ Polysomnographic recordings (Oxford System/8 channels) were obtained with 2 EEG recordings, four electromyographic (EMG) recordings (two of lower limbs-EMGleg; 1 upper limb-EMGarm; 1 submandibular-EMGchin) and 2 oculograms (EOG). Upper limb EMG was included for comparison of muscle activity with lower limbs (deafferented). The schedule of activities during the 4 days the volunteers remained in the laboratory was: Day 1: laboratory examinations; application of a questionnaire to determine the volunteers' social class, ${ }^{13}$ neurological evaluations (clinical and CT scan), and polysomnographic recording (adaptation night). Day 2: Polysomnographic recording (1st recording night). Day 3: Physiological evaluation (cardiac evaluation and a test of incremental maximum effort, Cybex Met 300, with increments of $12.5 \mathrm{w}$ every $2 \mathrm{~min}$ until exhaustion); polysomnographic evaluation (2nd recording night). Day 4: Volunteers' check out. After a volunteer checked out there was no need for his return to the laboratory.

Data on total sleeping time were analyzed by the paired Student $t$ test, whereas the number of changes of stage, total time in REM sleep, number of awakenings, and leg movements (PLM + RLS) were analyzed by the Wilcoxon matched paired test. The level of significance was set at $P<0.05$.

\section{Results}

All volunteers were male athletes, with a mean age of $28 \pm 4.89$ years. From these, $42.8 \%$ belonged to the upper middle class, $50 \%$ belonged to the middle class, and $7.15 \%$, to the lower class. ${ }^{3}$

Comparison between basal night (before physical activity) and $12 \mathrm{~h}$ following the test of maximum effort revealed statistical differences in all of the parameters evaluated. Physical activity resulted in a reduction of all measurements (Table 1).

\section{Discussion}

Spontaneous report of sleep complaints within a specific population of spinal cord injured subjects is commonly observed. ${ }^{2}$ Some of these complaints seem to be lessened by orientated programs of physical activity, which result in the subject's social reintegration ending a process of ostracism and sedentarism. ${ }^{14}$

The present study, using direct parameters of evaluation (computerized polysomnography), demonstrated a significant reduction of the mean total sleeping time $(9.57 \%)$, in the number of changes of stage $(15.56 \%)$, in the number of awakenings $(31.05 \%)$ and in total time in REM sleep $(28.9 \%)$, indicating a change of sleep pattern of these subjects following physical activity. Other authors reported increased sleep contentment when interruption of sleep is followed by physical activity. ${ }^{15}$

A decrease of leg movements (PLM and RLS, $69.7 \%$ ) was also observed following physical activity. These data demonstrate that this type of manipulation can modulate or change the incidence of leg movements during sleep. Endorphins are released after physical activity, ${ }^{16}$ causing a reduction of leg movements. $^{17}$

The occurrence of PLM and RLS in patients subjected to general epidural anesthesia ${ }^{18}$ as well as the presence of a positive Babinski sign during nonREM sleep ${ }^{19-21}$ has been reported. The Babinski reflex is a neurological test of spinal release. All patients with total spinal transection have a Babinski sign present. Thus, there may be a relationship between leg movements observed in the studies by Takanori et $a l^{1}$ De Mello et $a l^{2}$ and Dickel et $a l^{3}$ and PLM and RLS. These leg movements may result from dopamine deficiency in the central nervous system, since their treatment involves the administration of dopaminergic and opioidergic agonists, similar to the treatment for Parkinson's disease. ${ }^{22,23}$ However, in this specific population, a peripheral dopamine influence is unlikely to occur, due to the spinal cord trauma. Release of endorphins after physical activity, may

Table 1 Polysomnographic parameters in spinal cord injured subjects in a basal situation (1st recording night) or $12 \mathrm{~h}$ after physical activity (2nd recording night)

\begin{tabular}{lcc}
\hline & 2nd recording night after \\
physical activity & $\begin{array}{c}\text { Level of significance } \\
\text { 1st recording night }\end{array}$ & $\begin{array}{c}\text { 2nasal } \\
\text { base }\end{array}$ \\
\hline Mean total sleep time (min) & $417.4 \pm 31.1$ & $399.1 \pm 30.8$ \\
No. changes of sleep stage & $93.4 \pm 22.8$ & $78.9 \pm 14.9$ \\
Mean total time in REM (min) & $121.3 \pm 59.6$ & $86.2 \pm 51.0$ \\
No. of awakenings & $43.4 \pm 13.8$ & $29.9 \pm 13.0$ \\
No. of leg movements (PLM + RLS) & $33.0 \pm 54.1$ & $<.04$ \\
\hline
\end{tabular}


thus, cause a reduction of leg movements. Recently, ${ }^{16}$ an increase of plasma $\alpha$-endorphin, normalization of cortisol levels and a reduction of depressive symptoms in spinal cord injured subjects submitted to a program of physical activity with use of functional electrical stimulation of their paralysed lower limbs was demonstrated.

In conclusion, the practice of physical activity by spinal cord injured subjects can help to minimize sleep complaints, in particular those related to leg movements.

\section{References}

1 Takanori I, Kazuhiko K, Hitoshi T. Sleep related periodic leg movements (noturnal myoclonus) due to spinal cord lesion. $J$ Neurolog Sci 1991; 104: 13-18.

2 De Mello MT, Natal CL, Cunha JM, Tufik S. An epidemiologic study of sleep and complaints of subjects with spinal cord injury. Sleep 1994; 23: 356.

3 Dickel MJ, Renfrow SD, Moore PT, Berry RB. Rapid eye movement sleep leg movements in patients with spinal cord injury. Sleep Res 1994; 17: 733-738.

4 Ekbom KA. Restless legs. Acta Med Scand Suppl 1945; 158: 123

5 Lugaresi E, Coccagna C, Montovani M, Lebrun R. Some periodic phenomena arising during drowsiness in man. Electroenceph Clin Neurophysiol 1972; 32: $701-705$.

6 Montplaisir J, Godbout R, Pelletier G, Warnes H. Restless legs syndrome and periodic limb movements during sleep. In: Kryger MH, Roth T, Dement WC, editors. Principles and practice of sleep medicine 1994; 2nd ed., WB Saunders Company, Philadelphia: pp 589 .

7 Del Giglio SB. Estudo da ocorrência de queixas de insônia, de sonolência excessiva diurna e das relativas às parassonias na população adulta da cidade de São Paulo. São Paulo: pp 159.

8 De Varies HA. Immediate and long effects of exercise upon resting muscle action potential level. J Sports Med 1968; 8: 1 - 11 .

9 Ransford CP. A role for amines in the antidepressant effect of exercise. Med Sci Sports Exerc 1982; 14: 1-10.
10 Bulbulian R, Darados BL. Motor neuron excitability: the Hoffmann reflex following exercise at low and high intensity. Med Sci Sports Exerc 1986; 18: 697-702.

11 Rechtschaffen A, Kales A. Manual of standardiozed terminology techinique, and scoring for sleep stages of human subjects. 4th ed., UCLA, Los Angeles.

12 Jasper HH. The ten-twenty electrode system of the international federation. Electroencephalogr Clin Neurophysiol 1958; 10: 371 375.

13 ABIPEME Proposição para um novo critério de classificação sócio-econômica, MIMEO, 1978.

14 Kenneth HP. Introduction: exercise capacities and adaptations of people with chronic disabilities - current research, future directions, and widespread applicability. Med Sci Sports Exerc 1993; 25: $421-422$.

15 Bunnell DE, Bevier WC, Horvath SM. Sleep interruption and exercise. Sleep 1984; 7: $261-271$.

16 Twist DJ et al. Neuroendocrine charges during functional electrical stimulation. Am J Phys Med Reab 1992; 71: 156-163.

17 Schenck CH, Hurwitz TD, Bundlie SR, Mahowald MW. Sleeprelated eating disorders: Polysomnographic correlates of heterogeneous syndrome distinct from daytime eating disorders. Sleep 1991; 14: 419-431.

18 Watanabe S, Ono A, Naito H. Periodic leg movements during either epidural or spinal anesthesia in an elderly man without sleep-related (nocturnal) myoclonus. Sleep 1990; 13: 262 - 266.

19 Fujiki A et al. The Babinski reflex during sleep and wakefulness. Electroencephalogr Clin Neurophysiol 1971; 31: 610-613.

20 Smith RC. Relationship of periodic movements in sleep (nocturnal myoclonus) and the Babinski sign. Sleep 1985; 3: $239-243$.

21 Smith RC. Confirmation of Babinski-like response in periodic movements in sleep (noturnal myoclonus). Biol Psychiat 1987; 22: $1271-1273$.

22 Brodeur C, Montplaisir J, Godbout R, Mariner R. Treatment of restless legs syndrome and periodic movements during sleep with 1-dopa: a double-blind, controlled study. Neurology 1988; 38: $1845-1848$.

23 Staedt $\mathrm{J}$ et al. Dopamine D2 receptor alteration in patients with periodic movements in sleep (noturnal myoclonus). J Neural Trans 1993; 93: $71-74$. 